\section{Muito além dos nutrientes: experiências e conexões com crianças autistas a partir do cozinhar e comer juntos}

\author{
Far beyond nutrients: experiences and connections \\ with autistic children based on cooking and \\ sharing meals
}
Mucho más allá de los nutrientes: experiencias y conexiones con niños autistas a partir de
cocinar y comer juntos

Bruna Muratti Ferraz de Oliveira 1

Maria Fernanda Petroli Frutuoso 1

doi: 10.1590/0102-311X00132020

\section{Resumo}

Este estudo indagou como ampliar a análise da alimentação de crianças autistas, considerada inadequada pela seletividade alimentar ou pela dificuldade de interação nos momentos das refeições, atribuídas a alterações no processamento sensorial e a dificuldades sociais, comunicativas e cognitivas descritas no transtorno. A partir da perspectiva etnográfica, foi realizada observação participante, com registro em diários de campo, de oficinas culinárias com crianças/adolescentes autistas com vistas a analisar as relações que as crianças estabelecem com o alimento e os utensílios, com o espaço físico, entre elas e com adultos. Os registros foram analisados a partir da noção de experiência de Bondía e da Teoria Ator-Rede. Os dados produzidos mostraram singularidades na realização das tarefas de cozinhar e na aceitação das receitas. Algumas crianças não comeram os alimentos, mas cheiraram, lamberam e manipularam os ingredientes em momentos de experimentação, a partir da mediação dos profissionais, facilitadora da conexão das crianças com a comida e o comer. As interações estabelecidas com alimentos e utensílios apontam para a importância da comida e do cozinhar como mediadores da conexão das crianças com seus pares, com os adultos e com o mundo. Essa experiência rompeu com a valorização homogeneizadora das dificuldades de interação das crianças autistas e reforçou a comensalidade como ferramenta de construção de redes de cuidado. Pensar a alimentação dessas crianças em uma perspectiva ampliada é valorizar a subjetividade, a relação com o alimento e a interação entre pessoas nos momentos das refeições para além da compreensão biológica restrita aos nutrientes.

Nutrição da Criança; Culinária; Transtorno do Espectro Autista;

Relações Interpessoais espondência

M. F. P. Frutuoso

Universidade Federal de São Paulo.

Rua Silva Jardim 136, Santos, SP 11050-020, Brasil.

fernanda.frutuoso@unifesp.br

1 Universidade Federal de São Paulo, Santos, Brasil. 


\section{Introdução}

Comer é um ato social e multissensorial cotidiano 1,2. Para além do aspecto biológico da ingestão de nutrientes e da relação da dieta com o adoecimento, as práticas alimentares compreendem a seleção e a compra dos ingredientes; a manipulação e o modo de preparo dos alimentos; as refeições realizadas e os alimentos ingeridos 1,3 .

É na infância que se inicia a construção de hábitos, incluindo os alimentares e os ambientes, tanto domiciliar como escolar, podendo potencializar os processos educativos e de cuidado, bem como as relações interpessoais nessa fase da vida. O convívio entre os pares, com familiares e educadores, entre outros, propicia interações que contribuem para o desenvolvimento social da criança, sendo a comida um veículo importante de socialização. A comensalidade - conviver à mesa, comer e beber em conjunto - é um rito de agregação nos espaços alimentares compartilhados: no lar, na escola, no trabalho, nos restaurantes comerciais, fortalecendo laços e relações afetivas entre os grupos 1,3,4,5.

Para crianças autistas, essas questões são colocadas em xeque diante das dificuldades persistentes na comunicação e interação social, bem como nos padrões restritos e repetitivos de comportamento, interesses ou atividades, descritos na quinta edição do Manual de Diagnóstico e Estatístico de Transtornos Mentais (DSM-5), da Associação Americana de Psiquiatria 6. As dificuldades e os padrões têm impacto direto no cotidiano das famílias, inclusive na alimentação - ato social repetido várias vezes ao dia tornando o momento das refeições difíceis, seja na interação com pessoas ou no consumo alimentar considerado monótono e limitado 7,8.

Essas ponderações trazem desafios para a produção de conhecimento sobre alimentação de crianças autistas. No campo científico da Nutrição, esse tema é abordado, predominantemente, em estudos do hemisfério norte voltados aos aspectos fisiológicos da alimentação como, por exemplo, a exclusão de alimentos - e o reforço a condutas prescritivas e restritivas - visando à melhoria de sinais e sintomas 9,10,11. Estudos também reforçam a presença marcante da seletividade alimentar, associada a fatores sensoriais como cheiro, textura, cor e temperatura 7, e confirmada pelos pais que referem, por exemplo, a preferência dos filhos por alimentos de textura crocante e de sabor salgado 12 .

O comportamento sensorial atípico foi incorporado como um critério diagnóstico dos transtornos do espectro autista na DSM-5 6, e estudos internacionais discutem as possíveis disfunções no processamento sensorial de autistas como causas de alterações comportamentais, incluindo a seletividade alimentar e as tensões durante as refeições. Ainda que essa perspectiva, estritamente biológica, resulte em classificações fenotípicas e intervenções relacionadas à autorregulação, não existe consenso quanto à relação entre processamento sensorial e alimentação em autistas 13,14,15,16.

Esses achados não consensuais sobre a alimentação de crianças autistas, entre outros, são amplamente propagados por profissionais de saúde e pela mídia, desconsiderando os contextos, as vivências e as particularidades das relações que essas crianças estabelecem com o alimento, o comer e as formas com que as famílias lidam com essas questões. O reconhecimento das diferenças entre todas as crianças, incluindo as autistas, para além de reforçar intervenções que tentam alcançar comportamentos normais e padronizados, deve valorizar a variação e os processos alcançados a partir das experiências que as crianças estabelecem com o mundo 17.

Diante da complexidade do ato de se alimentar e das dificuldades apontadas na alimentação de crianças autistas, é possível ampliar as análises dos momentos compartilhados envolvendo alimentos? É possível criar possibilidades não patologizantes e distantes da perspectiva nutriente-centrada que ampliem a análise da alimentação de crianças autistas a partir da sensorialidade e comensalidade? Essas questões nortearam este estudo que teve como objetivo descrever e analisar as relações que as crianças autistas estabelecem em atividades em grupo envolvendo alimentos.

\section{Produção de dados}

Foi realizada pesquisa etnográfica a partir da observação participante das atividades institucionais supervisionadas com crianças e adolescentes autistas, realizadas em grupo e com alimentos, denominadas oficinas culinárias. 
A observação participante, como instrumento da pesquisa etnográfica, parte do princípio que, para conhecer certas dimensões de um contexto, grupo ou sociedade, são necessárias a aproximação e a vivência do pesquisador com tais circunstâncias, pois existem elementos que não são evidenciados superficialmente e que requerem um mergulho aprofundado para serem vistos e compreendidos 18,19. A participação efetiva do pesquisador na realidade estudada propõe um deslocamento do que é familiar, tomando o lugar tanto de participante como de observador das vidas em estudo 19. Assim, a relação pesquisador e pesquisado se expande continuamente, na medida em que ambos vivenciam experiências em um determinado contexto, possibilitando olhar para o que está implícito 18,20.

Esta pesquisa foi realizada na Associação Amigos dos Autistas de Sorocaba (AMAS; (http://www. amassorocaba.org.br/), São Paulo, entidade sem fins lucrativos que atende crianças autistas e famílias desde 1994, com equipe interprofissional composta por psiquiatra, psicólogo, psicopedagogo, pedagogo, auxiliares educacionais, educador físico, terapeuta ocupacional, fonoaudiólogo, assistente social e nutricionista.

As oficinas culinárias foram realizadas em grupos fixos, definidos de acordo com a disponibilidade da criança presente na AMAS no contraturno escolar (período matutino ou vespertino), com duração de aproximadamente 60 minutos. A oficina, como ferramenta metodológica, configura-se como espaço de negociação de sentidos que permite deslocamentos e contradições, a partir de diferentes modos discursivos, como a fala e os movimentos corporais, entre outros, em processos de subjetivação e produção coletiva 21. Reforçamos a oficina, neste estudo, como um lugar de experimentar e trocar, em uma ambiência que propiciou a experiência, a cooperação e o fazer/estar juntos. Nesse sentido, os encontros buscaram promover experiências com o alimento e com o comer, respeitando as particularidades das crianças, com ênfase na autonomia para a realização de atividades cotidianas.

Participaram de cinco oficinas culinárias (cupcake, pizza, salada de frutas, pão de queijo e pudim) 17 crianças e adolescentes brancos, de 3 a 15 anos de idade, atendidos na AMAS e sem relato/diagnóstico de alergia alimentar. Nesse grupo, quatro crianças não interagiam verbalmente, e, entre as demais crianças com comunicação verbal, havia algumas que pronunciavam sons, sem formar sílabas/ palavras e com episódios ecolálicos (repetição de sons e falas). Quanto às condições socioeconômicas, as famílias apresentavam renda média mensal entre um a três salários mínimos, sendo, em alguns casos, complementada por benefícios.

Todas as crianças/adolescentes presentes na AMAS no momento das oficinas foram convidadas a participar e incluídas nos encontros conduzidos por terapeuta ocupacional, nutricionista, estagiários de terapia ocupacional e pedagogia e, eventualmente, por psicóloga e psicopedagogo. Esses profissionais tinham contato cotidiano com os participantes das oficinas há, no mínimo, seis meses. As oficinas ocorreram em ambos os períodos, o que permitiu que fossem realizadas mais de uma vez, e que as crianças participassem de mais de um encontro.

Foram observados o espaço físico (estrutura, layout e fluxo; equipamentos e móveis; cores e iluminação; sons; sensação térmica), os participantes (profissionais e crianças) e as atividades (organização, duração, objetivo, tarefas, atitudes e sensações; comunicação; interações com o ambiente, alimentos e utensílios, entre crianças e profissionais).

Diários de campo foram construídos para o registro da observação, com a escrita do vivido, do que foi percebido do vivido, assim como as angústias, contradições, dúvidas, alegrias e incertezas, bem como os atravessamentos da experiência de campo 22.

Para a análise do material produzido, foram elaboradas tabelas com a descrição do espaço físico, participantes e atividades. Em seguida, foram selecionados trechos dos diários que ilustravam as experiências e as conexões com a comida e o comer.

O olhar para os dados produzidos foi orientado pelo conceito de experiência, definida por Bondía 23 (p. 21) como "o que nos passa, nos acontece, nos toca. Não o que se passa, o que acontece, ou o que toca". Um encontro ou uma relação com algo que se prova, que se apodera do sujeito, formando-o e transformando-o. A experiência requer parar ao pensar, olhar, escutar, falar e sentir, requer atenção aos detalhes, suspender a opinião, o juízo, a vontade, o automatismo da ação, enfim, dar-se tempo e espaço. Assim, o saber da experiência - adquirido a partir de como se dá sentido aos fatos - é um saber particular e subjetivo, no qual duas pessoas, ainda que enfrentem o mesmo acontecimento, não passam pela mesma experiência 23 . 
Essa concepção permeou a presença da pesquisadora - que também era a nutricionista da AMAS - em todas as oficinas culinárias, interagindo com crianças e profissionais e registrando a experiência e reflexões nos diários. Esses papéis concomitantes, de observadora e nutricionista, permitiram a expansão e o aprofundamento da relação pesquisador e pesquisado e da experiência de cozinhar e comer juntos, com ressonâncias sobre as práticas do nutricionista e sobre a produção de conhecimento na área de Alimentação e Nutrição. Trata-se de uma aposta na implicação da profissional que, ao se juntar às crianças e aos profissionais na experiência das oficinas, coloca, em análise, a sua própria prática em um processo singular de reflexão e transformação do saber-fazer do nutricionista.

Outro referencial teórico de análise foi a Teoria Ator-Rede, preconizada por Bruno Latour 24 e Annemarie $\mathrm{Mol}$ 25,26. que analisa o encontro e a interação entre humanos e não humanos, sem distinção, constituindo redes em processos de cuidado.

Da análise dos dados, emergiram dois imbricados temas: (1) sobre as oficinas, o ambiente e as conexões; (2) sobre o alimento como mediador de interações.

Esta pesquisa foi aprovada pelo Comitê de Ética em Pesquisa da Universidade Federal de São Paulo, parecer no 1.867.143 de 14 de dezembro de 2016, e os pais assinaram o Termo de Consentimento Livre e Esclarecido. Foram usados nomes fictícios para as crianças, seguidos da idade.

\section{Resultados e discussão}

\section{Sobre as oficinas, o ambiente e as conexões}

As oficinas aconteceram no refeitório da AMAS: um espaço coberto e com iluminação natural, com porta que o separa das outras áreas/salas e portão para acesso à área externa. Nesse espaço há uma mesa redonda, cadeiras, armário, balcão de apoio, pia e uma despensa com um forno micro-ondas, geladeira e prateleiras.

As receitas foram escolhidas levando-se em conta a estrutura física e os equipamentos disponíveis, e, a depender da preparação, as atividades envolveram trabalho motor (preensão), força muscular, coordenação motora fina, noção de espaço, quantidade, tempo e interação com alimento (experiências sensoriais e aceitação/degustação). Outra intencionalidade na escolha das preparações foi a diversidade de texturas e consistências (do pudim - gelatinosa/cremosa; da massa da pizza - crocância; do cupcake - maciez), de cores e odores (das frutas; das massas e dos confeitos do cupcake) e de sabores que poderiam compor um campo diverso de experimentação sensorial.

De uma forma geral, os alimentos/ingredientes foram apresentados às crianças que, sentadas ao redor da mesa, tinham total liberdade para contato e degustação. Em seguida, as crianças foram convidadas a preparar as receitas, com auxílio dos profissionais quando necessário, e, ao final, a experimentar as preparações. Havia, também, liberdade para movimentação e circulação no refeitório.

$\mathrm{Na}$ oficina de cupcake, as crianças observaram o preparo da massa que foi dividida em partes, coloridas com corantes comestíveis (amarelo, azul, rosa e verde) e acondicionadas em bisnagas, manuseadas pelas crianças que preenchiam as forminhas de papel e decoraram os bolinhos com cobertura e confeitos. Na oficina de pizza, todos os ingredientes para a cobertura foram apresentados para as crianças, que receberam um disco individual de massa e ingredientes para que preparassem a pizza de sua preferência. Para a salada de frutas, os profissionais apresentaram as frutas inteiras (melancia, laranja, abacaxi, kiwi, maçã, morango, uva, manga, banana e mamão) para que as crianças pudessem tocá-las e, em seguida, acompanhar o preparo. As crianças participaram de todo o processo de preparo do pão de queijo e do pudim: mistura dos ingredientes, porcionamento e cocção.

As oficinas culinárias compuseram um mosaico de interações materiais e imateriais em um processo múltiplo, fluido e imprevisível de contato entre pessoas, com alimentos e utensílios, disponibilizados para as tarefas de cozinhar e comer, e com o espaço físico também: móveis, instalações e outros alimentos disponíveis no refeitório e outros profissionais.

As crianças estabeleceram conexões com o ambiente. Ao chegarem ao refeitório, por exemplo, algumas apresentaram resistência ao visualizar o espaço físico, no início e/ou durante a atividade, chorando e mantendo-se em pé próximas à porta. Algumas se sentaram, outras interagiram com os 
materiais dispostos sobre a mesa, e outras ficaram em pé. Conexão também observada quando perceberam a entrada do profissional no refeitório:

"O pedagogo entrou para pegar café que estava na pia. Pedro [7 anos] ficou olhando. O pedagogo ofereceu, e Pedro aceitou e tomou".

"O psicopedagogo perguntou a Davi [15 anos] o motivo de estar em pé e no canto da parede, e Davi pronunciou um comercial de supermercado da cidade. O psicopedagogo, então, perguntou se ele iria ficar ali por muito tempo ou se iria dormir ali. Davi respondeu: dormir [fechou os olhos, uniu as mãos e as colocou ao lado do rosto], escova dente antes e faz oração. Qual oração? perguntou o psicopedagogo. Davi discorreu uma oração, com os olhos fechados, em pé, no canto da parede".

Em todas as oficinas culinárias, houve conexão marcante das crianças com os profissionais, que se posicionavam entre elas, alternando períodos em pé e sentados. Em alguns momentos, as crianças se sentaram no colo dos estagiários, adotando ação mais observadora. Em outros, participaram ativamente das tarefas, independente da habilidade em realizá-las:

"Perguntei se Vitor [9 anos] gostava de bolo. Ele disse que sim, olhou para as bisnagas na mesa e contou: um, dois, três... Montou os bolinhos coloridos utilizando as quatro cores, como a terapeuta ocupacional orientou e falou baixinho as cores quando ela as mencionou. Tocou no bolinho pronto, disse quente e começou a soprar".

"Perguntei se Arthur [10 anos] gostaria de colorir, ele balançou a cabeça sinalizando não. Então, sugeri fazer bolinhas com as mãos para moldar os pães de queijo. Coloquei um pouco da massa em sua mão. Arthur deslizou as mãos, fazendo um rolinho e disse não consigo".

Mesmo nos momentos de recusa em preparar e/ou consumir os alimentos/preparações, as crianças sustentaram interações com os profissionais:

"Miguel [4 anos] interagiu quando eu cortava as frutas, pronunciando os nomes e as cores, sempre falando que não gostava. Mostrei a salada de frutas pronta para Felipe [8 anos] e perguntei se ele tinha achado colorida e bonita, ele disse que era feia. Perguntei se ele queria experimentar, e ele recusou. Coloquei a salada de fruta em uma caneca e ofereci a Lucas [3 anos] que também recusou. A psicóloga perguntou para Felipe de qual fruta ele gostava, e ele respondeu chocolate. Ela disse que chocolate não era fruta e repetiu a pergunta. Felipe respondeu laranja".

No campo das interações, as crianças não hesitaram em indicar aos profissionais sobre a demora em alguma etapa da receita e sobre a quantidade suficiente de alimento preparada e/ou consumida, recusando-se a comer mais:

"Arthur [10 anos] falou: tá demorando muito. Comeu seu pão de queijo. Ofereci um que Mateus [4 anos] havia feito, azul. Ele mordeu um pedaço, fez careta e devolveu ao prato".

"Vitor [9 anos], ao ver a terapeuta ocupacional fazendo mais bolinhos, disse: chega. A terapeuta ocupacional perguntou se não queria mais, ele balançou a cabeça sinalizando não e repetiu chega. Ela disse que estava fazendo para outras pessoas".

Esses trechos vão apontando para a materialidade de um corpo - das crianças autistas - que é afetado e se deixa afetar. Esse corpo se torna sensível ao que está ao seu redor quando em ação com outras figuras humanas (os pares e os profissionais) e não humanas (alimentos, utensílios, móveis, grades, mesa). Nesse sentido, esses elementos-atores vão estabelecendo uma rede, configurando artifícios, sensações e experiências e propiciando um corpo, a partir de um vasto registro do vivido, da realidade e do mundo 24,27 .

O mesmo acontece com a equipe. Crianças e profissionais, coletivamente, medeiam interações, tendo em vista que geram uma ação, que produzem movimento e diferença. As conexões e redes são, portanto, construídas na própria pessoa e fora dela, em associação com outras entidades humanas e não humanas 28 .

Nesta experiência, foi marcante, também, a interação entre as crianças, tanto na realização das tarefas propostas nas oficinas, incentivando os pares, quanto em manifestações de afeto:

"A terapeuta ocupacional abriu o pacote do pó, entregou ao Pedro [7 anos] e o orientou que despejasse na tigela, ele executou sem dificuldades. Pedro disse baixinho: dentro, dentro, e, logo em seguida, Mateus [4 anos] disse: super Pedro".

"Vitor [9 anos] levantou-se e sentou-se em uma cadeira ao lado de Davi [15 anos] que o olhou e disse: beijo no Vitor, que balançou a cabeça sinalizando sim. Davi deu um beijo no rosto de Vitor".

Afeto também demonstrado por Felipe (8 anos) que pediu para levar um cupcake ao irmão que, frequentemente, o acompanha à AMAS junto com sua mãe. E ainda sobre a interação entre as crianças, 
em alguns momentos, foram observadas falas de repreensão ao colega, como quando uma das crianças levou a colher à boca e lambeu o molho. Outra criança, ao perceber, disse: "Não experimentar colher!". Em outro momento, uma das crianças chorou quando o colega pegou a massa que estava manipulando: "Caio [7 anos] pegou um pedaço da massa do Paulo [7 anos] que chorou. A estagiária devolveu".

As crianças foram agindo com e conforme o que estava no entorno, mostrando uma miríade de possibilidades de interações com pessoas e ambiente que podem, em certa medida, contradizer a literatura que restringe a análise da alimentação às dificuldades persistentes na comunicação e na interação social dos autistas, bem como às atipias sensoriais. A AMAS é um cenário de atores - humanos e não humanos - capaz de produzir diversas ambiências para novas e criativas interações, capaz de produzir redes.

Nos espaços educativos, cabe repensar as atividades para crianças autistas a partir de ações que, geralmente, distanciam-se das perspectivas educacionais mais hegemônicas, na medida em que os autistas, muitas vezes, não seguem os padrões de respostas já conhecidos e associados a um aprendizado significativo, o que não significa que não aprendam ${ }^{29}$. Nessa experiência, as crianças autistas formaram corpos afetados pela interação com o meio/mundo, em apostas provisórias de sociabilidade. $\mathrm{O}$ cozinhar e o comer, como ações práticas em espaço educativo e de cuidado, permitem deslocamentos e movimentos, permitem aprendizados.

As crianças reforçaram o caráter coletivo da alimentação, orgânico e compartilhado, mesmo diante das reiteradas dificuldades de interação descritas no transtorno. Há um jogo de relações que rompe fronteiras. Múltiplos regimes de interferências: alimentos, utensílios, profissionais, crianças, ambiente que permitem atitudes e ações diversas, na complexa teia de relações entre humanos e não humanos que envolvem a comida e o comer. As redes vão, portanto, sendo tecidas a partir de várias entradas, vários movimentos concomitantes.

Dessa forma, a experiência reforçou o papel da comida compartilhada na interação social e afetiva, que, no caso, refere-se ao cenário da AMAS. Outros cenários podem compor as diversas camadas de interações com os alimentos dessas crianças, como escola, domicílio, restaurantes, casa de amigos e familiares, ampliando possibilidades e conferindo complexidade à alimentação desse grupo.

\section{Sobre o alimento como mediador de interações}

O olhar para as oficinas requer desconstrução das concepções que permeiam o transtorno do espectro autista e abertura para o imprevisível do preparo de alimentos e refeições compartilhadas, possibilidades que não necessariamente se configuram como momentos de tranquilidade e controle. $\mathrm{O}$ estar junto e o compartilhar as experiências que emergem das singularidades das crianças autistas permitem olhar para as distintas formas de ser, sentir, alimentar e nutrir.

Diante das sensações e conexões que envolvem a alimentação, nesta experiência, percebeu-se expressivamente a relação com os alimentos. Cheirar e brincar com o alimento, recusar-se a tocar, lamber e não comer foram algumas das atitudes apresentadas pelas crianças, apontando a sensorialidade presente no transtorno do espectro autista, como nos trechos nos quais uma criança cheira os ingredientes do cupcake, e outra lambe as frutas, sem comê-las:

"Alice [11 anos] cheirou todas as bisnagas antes de despejar as massas. João [9 anos] pegou alguns granulados com os dedos e, em seguida, despejou o copinho de granulado em cima do bolinho. Alice também cheirou a bisnaga da cobertura e os granulados que pegou nas mãos, comeu os granulados que estavam em cima do bolinho e também os caídos no prato".

"Vítor [9 anos] já foi tocando as frutas e levando-as à boca. Lambia algumas e outras, como a uva, colocava na boca e cuspia. Não engoliu nenhuma”.

Esses relatos podem se aproximar à discussão de uma fisiologia sensorial atípica em autistas, o que pode causar aversão ou desconforto a determinadas sensações como toque, consistências e ruídos, entre outros, além de estar relacionada à seletividade alimentar 30,31.

Por outro lado, a interação que as crianças estabelecem com e por causa dos alimentos pode compor e ampliar a discussão sobre alimentação no transtorno do espectro autista, quando pensadas a partir de elementos não humanos - os alimentos e utensílios - na construção de conexões, expressadas pelos corpos nas tarefas de cozinhar e comer e, também, por outras linguagens. As crianças, ao cheirar, tocar, colocar à boca e cuspir, interagiram com os alimentos em ações distintas das esperadas 
nos tradicionais modos de preparo das receitas. Nessa perspectiva, rastreou-se o inesperado, a imprevisibilidade, o surpreendente e acolheu-se a diversidade, a subjetividade, a partir de um olhar difuso e dinâmico para a alimentação dessas crianças.

Da mesma forma que profissionais e crianças se configuram como mediadores de interações, os alimentos também o são, na medida em que viabilizam uma ação, uma conexão em uma rede que modifica algo, sem qualquer hierarquia entre os mediadores 28 . Mediar é "interferir, é fazer a diferença na produção de um efeito e, além disso, não se trata de uma ação exclusiva dos humanos" 32 (p. 116). Assim, "quanto mais mediaçoes, mais fácil adquirir um corpo que seja sensível" 27 (p. 9), possibilitando, a partir do afetar e ser afetado, uma leitura do mundo.

Essa perspectiva nos oferta a possibilidade de pensar a alimentação, nesse cenário, a partir de uma complexa e múltipla rede de conexões, com efeitos inesperados e surpreendentes. Interessa-nos, aqui, dar visibilidade aos efeitos traçados junto com as crianças autistas. Interessa-nos admitir o caos e permitir colocar o alimento à boca e não comer. Interessa-nos pensar na artesania da manipulação dos ingredientes, do cozinhar junto como mote para novas e outras formas de entender a comida e de exercer a prática do nutricionista.

Admitir as muitas formas de interagir com o alimento, que resultam em muitas formas de cozinhar e comer, significa acolher todas as possibilidades durante as oficinas, da aceitação e recusa à manipulação dos ingredientes:

"Pedro [7 anos] e Arthur [10 anos] tocaram nos frios com a ponta dos dedos. Davi [15 anos] não quis tocar no presunto e nem colocou em sua pizza, falando não quando mostrei o presunto e o orégano".

Da aceitação e recusa à experimentação dos ingredientes e receitas:

"A terapeuta ocupacional pediu para que ela mordesse o bolinho, e ela continuou comendo apenas os granulados e lambendo a cobertura de chocolate. Davi [15 anos] colocou cobertura e granulado e não mostrou interesse em comer. A terapeuta ocupacional perguntou se ele queria comer, e ele disse: não, obrigado".

Uma das crianças, por exemplo, aceitou experimentar o pudim somente quando a sensação de gelado foi minimizada:

"Alice [11 anos] teve reação de ânsia ao experimentar o pudim, e ela disse: gelado. Me lembrei que ela não aceita alimentos gelados e transferi o pudim para outro copo plástico e ofereci à Alice, que pegou o copo e experimentou o pudim".

Algumas crianças manipularam os alimentos de forma lúdica, como Lucas (3 anos) que se recusou a tocar em algumas frutas, mas se interessou por rolar as laranjas na mesa, e Paulo (7 anos) que se recusou a comer pão de queijo, mas "começou a fazer rolinhos pequenos e formar o trilho do trem na mesa". O lúdico aparece, também, nas associações entre as cores e desenhos animados:

"Davi [15 anos] relacionava as cores, pegou a bisnaga rosa e disse que era Peppa pig, a verde não compreendemos o nome em inglês que dizia ser um desenho, o amarelo ao 'sun' e apontou para o céu".

Os trechos vão compondo uma infinidade de possibilidades de interações, com diversos gradientes. Importante pontuar que o próprio ato de ingerir pode ser entendido como uma forte interação, na medida que o alimento é colocado para dentro do corpo, em interações múltiplas permeadas pelas funções fisiológicas e sociais da comida.

Dessa forma, as interações carregam mediações capazes de produzir permanências e movimentos, tendo em vista que os elementos se articulam, afetam-se mutuamente e se renovam. O alimento é, portanto, um mediador, e as oficinas se configuraram como espaços potenciais para a produção de interferências e mediações de caráter local, contingente e variável.

Foram acolhidos, também, os momentos em que as crianças aceitaram participar apenas de alguma das etapas das oficinas ou se recusaram totalmente a realizar a atividade:

"Coloquei um pouco de massa em um prato e mostrei ao Caio [7 anos], que teve reação de ânsia e empurrou o prato. Fiz uma bolinha com a massa e ofereci, ele olhou por alguns segundos, pegou e começou a rolar a massa na mesa. Coloquei mais massa em sua frente. Ele juntou à sua massa e continuou a enrolar na mesa. A terapeuta ocupacional colocou um pão de queijo assado na frente de Caio. Ele empurrou, ela empurrou de volta, e ele repetiu o movimento. Continuava a rolar a massa na mesa".

"José [6 anos] não quis tocar nos frios [nem tiras, nem ralado] e no orégano. Levantou-se em alguns momentos e subiu na cadeira uma vez. A terapeuta ocupacional cortou a pizza e ofereceu. José recusou. Paulo [7 anos] empurrou o prato com a massa que coloquei em sua frente. Sentei-me ao seu lado e falei que iríamos fazer 
pizza. Retomei o prato, apresentei a bisnaga do molho, ele pegou, despejou, porém logo se levantou e começou a chorar. Em alguns momentos, tampou o ouvido com as mãos".

"Lucas [3 anos] parecia estar em outro mundo, caminhava descalço, sorria e agarrava na grade em alguns momentos. Recusou o pudim, virou o rosto quando a estagiária ofereceu".

"Davi [15 anos] se levantou e foi para o canto da parede, entendi que realmente não queria participar".

Essas narrativas nos remetem às reiteradas dificuldades no manejo das refeições, especialmente diante da recusa em se alimentar, que convoca os familiares - e os profissionais - a reverem o enunciado e a expectativa da refeição como um momento calmo, controlado e limpo, em que as crianças comem com tranquilidade à mesa e aceitam alimentos variados. Ainda que essa seja uma experiência singular, em uma AMAS que recebe as crianças em contraturno escolar, ela não se aparta da reflexão de outras conexões e outras redes, com seus múltiplos enunciados que incidem cotidianamente umas nas outras, nas diferentes camadas que compõem a alimentação dessas crianças: a rede domiciliar, familiar, escolar, profissional, entre outras.

A ideia de recalcitrância - ou resistência - nos indica a possibilidade de recusar a realização das atividades e/ou tarefas. Essa recusa, nos processos de aprendizagem e de cuidado, pode contribuir para a construção de espaços nos quais cabe a diferença e onde as discordâncias não são um efeito a ser evitado. Para Melo 33 (p. 188), "realçar as diferenças quando a tendência for homogeneizar, torná-las planas quando a tendência for discriminar talvez seja uma boa estratégia nesse exercício de compor um mundo plural e comum".

Essa experiência aponta para o movimento do centro hegemônico da produção de conhecimento e práticas em Nutrição sobre o transtorno do espectro autista para a periferia, com inspiração para a construção de novos enunciados, a partir do deslocamento de objetivos, certezas e rotas, e para a invenção de novos lugares, linguagens e análises. São admitidos, assim, múltiplos e outros modos de se relacionar com a comida, sem ordenação e/ou controle.

Trata-se, portanto, de uma aposta de composição - e também ampliação - do olhar sobre a alimentação de crianças autistas e das práticas do nutricionista, para além do restrito diagnóstico do consumo de nutrientes e da orientação de dietas com restrição de substâncias para remissão de sintomas, que levam a práticas controladoras e à identificação de correções a serem feitas.

A aposta é de incluir a insistência nos processos mediados pelo alimento - de cozinhar e comer - que produzem e sofrem efeitos, que mobilizam mundos, criam idas e vindas, movimentam. Chorar, gritar, tapar os ouvidos, olhar para o nada foram ações presentes para que as oficinas acontecessem. Ordenamento e resistências ocorreram para que os encontros e conexões acontecessem. Elementos heterogêneos, humanos e não humanos, conectaram-se para que o cozinhar e comer juntos acontecessem.

As experimentações sensoriais, alimentares e de comunicação/interação aconteceram tanto para as crianças como para a pesquisadora, nutricionista da AMAS, que afetou e se deixou afetar pela experiência das oficinas culinárias. Tomando o caráter multiprofissional das oficinas e a implicação da pesquisadora em repensar a alimentação de crianças autistas na AMAS, os resultados dessa investigação foram, em conjunto com os outros profissionais e pais/responsáveis, validados e transformados em dois produtos: informações sobre alimentação disponibilizadas no site da AMAS e tirinhas para atividades educativas com as crianças 34 . Nessa perspectiva, mesclam-se teoria e prática, pesquisador e pesquisado, e assume-se que a análise consiste não apenas em olhar para o outro, mas em olhar para si mesmo, em transformação durante um processo de produção de conhecimento que se dá a partir do encontro com o outro 35. Trata-se de trabalhar com a contradição, com a produção de algo novo.

Para a equipe da AMAS, as oficinas iluminaram a multiplicidade distante da fragmentação, controle e vigilância que podem permear e permanecer nas práticas dos profissionais. Iluminaram a necessidade de fazer eco para a experiência cotidiana de comer, repetida várias vezes ao dia com atores humanos e não humanos e, no caso das crianças estudadas, sempre de responsabilidade e compartilhada com adultos. 


\section{Considerações finais}

Dessa experiência com a comida, é possível depreender o alimento como mediador de conexões que passam pelo campo sensorial: cheirar, tocar (ou se recusar a tocar), lamber, comer (ou não comer) e passar o alimento pelo corpo. As oficinas não se resumiram em apresentar o alimento à criança, a fim de promover interação, conhecimento e interesse em consumi-lo. Permitiram acolher as diferenças e perceber as complexas relações que as crianças autistas estabelecem em grupo (crianças e profissionais) e em ambiente institucional - com o alimento e o comer. Permitiram, também, perceber comportamentos e gestos que contrapõem descrições generalistas acerca do transtorno e que, de certa forma, norteiam compreensões restritas, direcionadas aos comprometimentos e às dificuldades como, por exemplo, a comunicação e a socialização, e ofuscam a multiplicidade de ações que potencializam as conexões.

As experimentações expressam os sentidos que a alimentação pode ter - na vida - e o desafio de (re)pensar a concepção que restringe a alimentação de autistas ao nocivo/patológico das recusas e rejeições alimentares que levam a práticas profissionais de ajustes e correções. Para além dos desfechos adversos à saúde, os achados deste estudo reforçam a necessidade de considerar a subjetividade e de valorizar as diferenças em tempos de homogeneização. É um convite para assumir a comida como campo do sensível a partir da realidade que se estabelece em companhia, ao redor da mesa, em um processo de constante redefinição que nem sempre pode ser previsto e/ou explicado.

\section{Colaboradores}

B. M. F. Oliveira e M. F. P. Frutuoso contribuíram na concepção e projeto do estudo, análise e interpretação dos dados, redação do artigo, revisão crítica relevante do conteúdo intelectual e aprovação final da versão a ser publicada. São responsáveis por todos os aspectos do trabalho na garantia da exatidão e integridade de qualquer parte da obra.

\section{Informações adicionais}

ORCID: Bruna Muratti Ferraz de Oliveira (00000002-1669-8453); Maria Fernanda Petroli Frutuoso (0000-0002-6078-5511).

\section{Referências}

1. Poulain JP. Sociologias da alimentação: os comedores e o espaço social alimentar. 2a Ed. Florianópolis: Editora da UFSC; 2013.

2. Breton D. Antropologia dos sentidos. Petrópolis: Editora Vozes; 2016.

3. Contreras J, Gracia M. A alimentação humana: um fenômeno biocultural. In: Contreras J, Gracia M, organizadores. Alimentação, sociedade e cultura. Rio de Janeiro: Editora Fiocruz; 2011. p. 109-46.

4. Morrison M. Sharing food at home and school: perspectives on commensality. Sociol Rev 1996; 44:648-74.

5. Sobal J. Sociability and meals: facilitation, commensality, and interaction. In: Meiselman HL, editor. Dimensions of the meal: the science, culture, business, and art of eating. Gaithersburg: Aspen Publishers; 2000. p. 11933.

6. American Psychiatric Association. Manual diagnóstico e estatístico de transtorno-DSM-5. 5a Ed. Porto Alegre: Artmed; 2014. p. 52-7.

7. Cermak SA, Curtin C, Bandini LG. Food selectivity and sensory sensitivity in children with autism spectrum disorders. J Am Diet Assoc 2010; 110:238-46. 
8. Suarez MA, Atchison BJ, Lagerwey M. Phenomenological examination of the mealtime experience for mothers of children with autism and food selectivity. Am J Occup Ther 2014; 68:102-7.

9. van De Sande MMH, van Buul VJ, Brouns FJPH. Autism and nutrition: the role of the gut-brain axis. Nutr Res Rev 2014; 27:199214.

10. Frye ER, Shannon R, Slattery J, MacFabe DF. Gastrointestinal dysfunction in autism spectrum disorder: the role of the mitochondria and the enteric microbiome. Microb Ecol Health Dis 2015; 26:10.3402/mehd.v26.27458.

11. Ferreira LBP. Um percurso sobre o autismo: história, clínica e perspectivas. Cadernos Deligny 2018; 1:110-9.

12. Schreck KA, Williams K. Food preferences and factors influencing food selectivity for children with autism spectrum disorders. Res Dev Disabil 2006; 27:353-63.

13. Case-Smith J, Weaver LL, Fristad MA. A systematic review of sensory processing interventions for children with autism spectrum disorders. Autism 2015; 19:133-48.

14. Boudjarane MA, Grandgeorge M, Marianowski R, Misery L, Lemonnier E. Perception of odors and tastes in autism spectrum disorders: a systematic review of assessments. Autism Res 2017; 10:1045-57.

15. Hand BN, Dennis S, Lane AE. Latent constructs underlying sensory subtypes in children with autism: a preliminary study. Autism Res 2017; 10:1364-71.

16. Uljarevic M, Baranek G, Vivanti G, Hedley D, Hudry K, Lane A. Heterogeneity of sensory features in autism spectrum disorder: challenges and perspectives for future research. Autism Res 2017; 10:703-10.

17. Pride in autistic diversity. Lancet 2016; 387:2479.

18. Rocha ALC, Eckert C. Etnografia: saberes e práticas. In: Pinto CRJ, Guazzelli AB, organizadores. Ciências humanas: pesquisa e método. Porto Alegre: Editora da Universidade Federal do Rio Grande do Sul; 2008. p. 9-24.

19. Angrosino M. Etnografia e observação participante. Porto Alegre: Artmed; 2009.

20. Magnani JGC. Etnografia como prática e experiência. Horizontes Antropológicos 2009; 32:129-56.

21. Spink MJ, Menegon VM, Medrado B. Oficinas como estratégia de pesquisa: articulações teórico-metodológicas e aplicações ético-políticas. Psicol Soc 2014; 26:32-43.

22. Mendes R, Pezzato LM, Sacardo DP. Pesquisa -intervenção em promoção da saúde: desafios metodológicos de pesquisar "com". Ciênc Saúde Colet 2016; 21:1737-45.
23. Bondía JL. Notas sobre a experiência e o saber da experiência. Rev Bras Educ 2002; 19:20-8.

24. Latour B. How to talk about the body? The normative dimension of science studies. Bod Soc 2004; 10:205-29.

25. Mol A. The body multiple: ontology in medical practice. Durham: Duke University; 2002.

26. Mol A. Actor network theory: sensitive terms and enduring. https://www.dasts.dk/wpcontent/uploads/Annemarie-Mol_Actor-Net work-Theory-Sensitive-Terms-and-EnduringTensions.pdf (acessado em 20/Mar/2017).

27. Coutinho FA, Goulart MIM, Pereira AF. Aprendendo a ser afetado: contribuições para a educação em ciências na educação infantil. Educ Rev 2017; 33:e155748.

28. Cavalcante RB, Esteves CJS, Pires MCA, Vasconcelos DD, Freitas MM, Macedo AS. The actor-network theory as a theoretical-methodological framework in health and nursing research. Texto \& Contexto Enferm 2017; 26:e0910017.

29. Martins ADF, Monteiro MIB. Alunos autistas: análise das possibilidades de interação social no contexto pedagógico. Psicol Esc Educ 2017; 21:215-24.

30. Twachtman-Reilly J, Amaral SC, Zebrowski P. Addressing feeding disorders in children on the autism spectrum in school-based settings: physiological and behavioral issues. Lang Speech Hear Serv Sch 2008; 39:261-72.

31. Ben-Sasson A, Hen L, Fluss R, Cermak SA, Engel-Yeger B, Gal E. A meta-analysis of sensory modulation symptoms in individuals with autism spectrum disorders. J Autism Dev Disord 2009; 39:1-11.

32. Melo MFAQ, Silva MA, Albuquerque EPT, Ramos LTM, Gonçalves DES, Oliveira MH, et al. Sucata vira brinquedo: tradução a partir de restos. Psicol Soc 2007; 19:114-21.

33. Melo MFAQ. Discutindo a aprendizagem sob a perspectiva da teoria ator-rede. Educ Rev 2011; 39:177-90.

34. Oliveira BM, Frutuoso MFP. Sem receita: deslocamentos do olhar da Nutrição sobre o comer de crianças autistas. Interface (Botucatu) 2020; 24:e190597.

35. Costa EAP, Coimbra CMB. Nem criadores, nem criaturas: éramos todos devires na produção de diferentes saberes. Psicol Soc 2008; 20:125-33. 
Abstract

This study examined ways to expand the analysis of diet in autistic children, widely considered inadequate according to food selectivity and/or difficulty interacting at mealtimes, attributed to alterations in sensorial processing and social, communicative, and cognitive difficulties. From an ethnographic perspective, a participant observational study was performed with field diary records and cooking workshops with autistic children and adolescents, aimed at analyzing the relations established by the children with the food and utensils, physical space, and between each other and the adults. The records were analyzed based on Bondia's notion of experience and Actor-Network Theory. The resulting data showed singularities in performing cooking tasks and accepting recipes. Some children did not eat the foods, but smelled, licked, and handled the ingredients in moments of experimentation through mediation by the educators, facilitating connection by the children with food and eating. The interactions established with foods and utensils highlight the importance of food and eating as mediators of the connection between autistic children and their peers, with adults, and with the world. This experience broke with the homogenizing value assigned to autistic children's difficulties with interaction and reinforced commensality as a tool for building networks of care. To conceive eating for these children from an expanded perspective means to value subjectivity, the relationship to food, and interaction with others at mealtimes, far beyond the biological understanding of the nutrients.

Child Nutrition; Cooking; Austism Spectrum Disorder; Interpersonal Relations

\section{Resumen}

Este estudio indagó como ampliar el análisis de la alimentación de niños autistas, considerada inadecuada por la selectividad alimentaria o por la dificultad de interacción en los momentos de las comidas, atribuidas a alteraciones en el procesamiento sensorial y dificultades sociales, comunicativas $y$ cognitivas descritas en el trastorno. A partir de la perspectiva etnográfica, se realizó una observación participante, con registro en diarios de campo, de talleres culinarios con niños/adolescentes autistas, con el fin de analizar las relaciones que los niños establecen con el alimento y utensilios, con el espacio físico, entre ellos y con adultos. Los registros fueron analizados a partir de la noción de experiencia de Bondía y de la Teoría Actor Red. Los datos producidos mostraron singularidades en la realización de las tareas de cocinar y en la aceptación de las recetas. Algunos niños no comieron los alimentos, pero los olieron, lamieron y manipularon los ingredientes, en momentos de esta experiencia, a partir de la mediación de los educadores, facilitadora de la conexión de los niños con la comida y el comer. Las interacciones establecidas con alimentos y utensilios apuntan a la importancia de la comida y del cocinar como mediadores de la conexión de los niños con sus compañeros, con adultos, así como con el mundo. Esta experiencia rompió con la valoración homogeneizadora de las dificultades de interacción de los niños autistas y reforzó la comensalía como herramienta de construcción de redes de cuidado. Pensar la alimentación de estos niños desde una perspectiva ampliada es valorar la subjetividad, la relación con el alimento, la interacción entre personas en los momentos de las comidas, para ir más allá de la comprensión biológica restringida a los nutrientes.

Nutrición del Niño; Culinaria; Trastorno del

Espectro Autista; Relaciones Interpersonales
Recebido em 19/Mai/2020

Versão final reapresentada em 12/Ago/2020

Aprovado em 04/Set/2020 